\title{
Islamic Geometric Design
}

\author{
Eric Broug
}

New York: Thames \& Hudson, 2013. 256 pages full color.

The subject of Islamic geometric design has been described in numerous ways: Keith Critchlow's Islamic Patterns and Syed Jan Abbas and Amer Shaker Salman's Symmetries of Islamic Geometrical Patterns, both highly esoteric interpretations; Owen Jones' Grammar of Ornament, Emile Prisse d'Avennes' L'Art arabe d'apres les monuments du Kaire, and Jules Bourgoin's Arabic Geometrical Pattern and Design, all descriptions of drawing collections; and even as a theme for countless "coffee table" books resplendent with glossy photographs of exotic patterns and colors.

Is it fair to evaluate this book without tending to imagine the previous categories of this study? Years ago I led a course on this topic and desperately tried to juggle the beautiful, historic, and hands-on practical manifestations of the sacred through drawing particular geometric patterns over and over 
again. For this course I needed to select chapters, or portions of the abovementioned texts in addition to the comprehensive works of K. A. Creswell in Early Muslim Architecture, Doris Behrens-Abou Seif's Mamluks of Cairo and Minarets of Cairo, as well as other architectural studies, and interpret and reconstruct the designs in order to teach them. It was a research project of sorts where the outcome was not textual but pedagogical.

While reading this text by Eric Broug, I felt that he had gone through a similar but far more prolonged process. His book stands alone for several reasons: the author (1) weaves knowledge of the historical, recognition of the beautiful, and reconstruction of the practical regarding patterns. The succinct explanatory text, incredible detailed photography in situ, and clear stepby-step diagrams converge to elucidate this rich material; (2) outlines the influence of other artistic traditions and the development of a clear type of "Islamic geometry" that is easily recognizable; and (3) concentrates on the design approach of craftspeople, which was separate and concurrent with the scientific study of geometry. This difference is important: craftspeople applied geometric patterns to various surfaces and were concerned with aesthetic compositions; whereas scientists contemplated the complex patterns in terms of mathematical geometries.

Broug summarizes the field's recent history (dating from the nineteenth century), beginning with Owen Jones' publication of designs of the Alhambra and other texts that helped him understand the practical side of design but did not show the steps. He mentions that some scholars focused on the geometric patterns' spiritual and cosmological interpretations; however, this statement is difficult to substantiate without the historical documentation of the craftspeople's motivation. He therefore chose to focus on the creative process, an approach shaped by his experience as an artist, designer, and researcher as well as his desire to present the material in the most straightforward manner. Broug draws from a variety of media to which geometric patterns were applied in order to from architecture and architectural elements (e.g., walls, floors, ceilings, doors, minbars, minarets, and domes) to manuscripts and various objects (e.g., vessels).

The book's six chapters are arranged in ascending order of visual complexity from "Basic Design Principles" and "Grids and Polygons" through three types of geometric design culminating with "Combined Geometric Design." It ends with a fifty-page appendix: "How to Create Designs."

Broug begins chapter 1, "Basic Design Principles," with the concept that geometric composition is necessarily a balance of rules and creativity. In practical terms, every design begins as a circle and a series of circles - however, these are relegated mostly to the background construction of geometric pat- 
terns; few circles appear in Islamic geometric design after the eleventh century. The mostly rectilinear geometry that emerged is sometimes embellished with vegetal forms to create "arabesques." Most categories of Islamic geometric design are based on the number of points on the stars used, which are commonly either four-, five-, and sixfold or multiples of these. Seven- and elevenpointed stars are very rare. Broug encourages the reader to draw each example to understand the composition as a process and not just an outcome.

This chapter outlines the importance of the design's context and the fact that the craftsperson had to accommodate and invent according to the specifics of size, location, and material, as well as to the overall grid, to arrange his/her patterns cohesively. It then runs through the meaning and application of regular and irregular polygons, visual anchors and layers, and examples to understand these principles. The seed of a question is then planted, and subtly addressed in the book's conclusion, regarding the ubiquity of geometric design across time and region in Islam.

Chapter 2, "Grids and Polygons," outlines the influence of grids from Roman mosaics and stonework on Islamic craftspeople in the Mediterranean region. However, the grids in Islamic design are never visible, unlike those of their predecessors. The grid allows for creativity and versatility, and identifying underlying grids allows one to discern how the compositions are created. Most grids are either rectilinear or triangular.

This chapter outlines the repeat units, symmetry, and reflection. This is key to the book's overall approach: how to deconstruct a seemingly complex design to understand its layers of patterns and methods of reconstruction. The book is full of detailed photographs and step-by-step colored diagrams for this very purpose. In many ways, the author is showing the reader how to see and read designs by breaking everything down to its simple components. Broug emphasizes that despite all of this, many patterns are not "perfect," for adjusting the designs is a sign of skill and creative spirit. Examples of these modifications are presented throughout the book.

Chapter 3, "Fourfold Geometric Design," begins a trio of chapters formulated around an ascending order of compositional "families." It begins with the most straightforward one, the fourfold family, and outlines such multiples as the eightfold in composition. Historical examples dating back to the eighth century are provided to trace its prominence throughout history. Such elements as "bowties" and "arrows" are introduced as key forms that unify the spaces between the stars. The author concludes with the reflection that fourfold geometry is the most likely pattern to combine with other designs within the same family and not within other families, such as five- or sixfold patterns. 
Chapter 4, "Sixfold Geometric Design," opens by declaring "the greatest variety of patterns in Islamic geometric design can be found in sixfold design" (p. 95) because it is the easiest to master and manipulate and has many possible elaborations. Examples in various media are deconstructed with explanations and drawings to create a consistently rich reading. The related twelvefold design is also examined (formed by either three multiples of squares or four multiples of triangles), and the methods of combining and modifying this pattern family are outlined. The author concludes by observing that twelvefold patterns are found in nearly every period and region. Although the flow of craftspeople, ideas, and influences cannot be fully determined, the twelvefold pattern proved to be a universal language of exploration in design and was understood because of its wealth of opportunities and ease of self-exploration.

Chapter 5, "Fivefold Geometric Design," outlines this family's unique design challenges. The ensuing deconstruction, however, does not begin with locating the underlying grid, but with finding the various recognized repeated groups - a much more complex reading of the much more complex compositional family. Craftspeople most likely used the "cut and paste" method to develop these designs. In addition, despite the higher number of design elements in fivefold design, most are drawn with only a few basic construction lines. Broug discusses the fivefold patterns outlined in the historical "Topkapi scroll" and emphasizes its importance as one of the few surviving documents that demonstrates geometric patterns. The chapter concludes that that fivefold design is a "creative universe of its own" and thus neither needs nor benefits from other geometric families.

In chapter 6, "Combined Geometric Design," the book's final chapter, Broug combines the previous families and analyzes the more complex seven- and elevenfold geometries. The chief challenge here is the connection of different star patterns and the resultant innovations. Combinations are outlined in ascending order of complexity. A subsection on the metal doors of Mamluk Cairo reveals innovative solutions in this category and is aptly deconstructed. Following this, the author discusses sevenfold and fourteenfold star patterns and summarizes the methods of combining ninefold star patterns with other stars (e.g., six, twelve, and eighteen). Other combinations, as well as the extreme difficulty of eleven and thirteen star compositions, are explained.

However, the leading difficulty is how to apply these combined geometries to convex and concave surfaces (i.e., exterior and interior of domes), given the required adjustments needed as regards their arrangement, distortion, and interstitial space design of star patterns to produce a pleasing final product. 
The author outlines several methods to discern the deconstruction of such compositions.

The chapter's conclusion, which also concludes the book, reflects on what motivated the creation of such extraordinary patterns and the important development of idiosyncrasies to make these compositions work. To the "trained eye and the unhurried mind," all of this can be revealed. In response to the first question posed in chapter 1, "Islamic geometric design is not just the artful intersection of lines. It is also about how a pattern or composition is embellished; what has the craftsmen added to make it more beautiful?" and this, ephemerally, unites the millions of craftsmen in the Islamic world through history and regions.

The generous Appendix, "How to Create Designs," outlines (in colored steps) the construction of three types of grids and nineteen different designs from the four-, five-, and sixfold families. The author references his previous text Islamic Geometric Patterns, should the reader wish to pursue the construction of more designs.

This book, which cannot be neatly categorized as "historical," "esoteric," or "coffee table," is uniquely comprehensive in covering a specific area of architectural and object surface elaboration. It is clearly written so that a total understanding of the material is possible for any interested reader - specialist and novice alike. I imagine that many a student and educator will enjoy this.

Tammy Gaber Assistant Professor of Architecture, School of Architecture Laurentian University, Sudbury, ON, Canada 